\title{
Mortality changes after grants from the Global Fund to Fight AIDS, tuberculosis and malaria: an econometric analysis from 1995 to 2010
}

\author{
Isabel Yan', Eline Korenromp ${ }^{2,3}$ and Eran Bendavid ${ }^{4,5^{*}}$
}

\begin{abstract}
Background: Since its founding in 2002, the Global Fund to Fight AIDS, Tuberculosis, and Malaria (Global Fund) has become the dominant multilateral health financier in low- and middle-income countries. The health impact of the Global Fund remains unknown because existing evaluations measure intermediate outcomes or do not account for preexisting and counterfactual trends.

Methods: We conducted an econometric analysis of data from all countries eligible to receive Global Fund grants from 1995 to 2010, prior to and during the Global Fund's activities. We analyzed three outcomes: all-cause adult (15-59 years), all-cause under-five, and malaria-specific under-five mortality. Our main exposure was a continuous longitudinal measure of Global Fund disbursements per capita. We used panel fixed effect regressions, and analyzed mortality trends controlling for health spending, health worker density (a measure of health system capacity), gross domestic product, urbanization, and country fixed-effects.
\end{abstract}

Results and discussion: We find that following Global Fund disbursements, adult mortality rate declined by $1.4 \%$ per year faster with every $\$ 10$ per capita increase in disbursements $(p=0.005)$. Similarly, malaria-specific under-five mortality declined by $6.9 \%$ per year faster $(p=0.033)$ with every $\$ 10$ high per capita Global Fund disbursements. However, we find no association between Global Fund support and all-cause under-five mortality. These findings were consistent after subanalyses by baseline HIV prevalence, adjusting for effects of concurrent health aid from other donors, and varying time lags between funding and mortality changes.

Conclusions: Grants from the Global Fund are closely related to accelerated reductions in all-cause adult mortality and malaria-specific under-five mortality. However, up to 2010 the Global Fund has not measurably contributed to reducing all-cause under-five mortality.

Keywords: Global Fund, Mortality, Outcomes evaluation

\section{Background}

Development assistance to the health sector of developing countries has increased by over 3-fold between 1990 and $2012[1,2]$. A central institution involved in this growth has been the Global Fund to Fight AIDS, Tuberculosis, and Malaria (Global Fund). From its founding in 2002 through the end of 2012, the Global Fund disbursed nearly $\$ 19$ billion (current USD) in development assistance to

\footnotetext{
* Correspondence: ebd@stanford.edu

${ }^{4}$ Division of General Medical Disciplines, Stanford University Stanford, Stanford, CA 94305, USA

${ }^{5}$ Center for Health Policy and the Center for Primary Care and Outcomes Research, Stanford University, Stanford, CA 94305, USA

Full list of author information is available at the end of the article
}

disease control programs in nearly 140 countries [3]. During this period, the Global Fund has become the dominant multilateral funder of health programs in low- and middleincome countries.

To date, the Global Fund has focused on financing HIV/AIDS, tuberculosis, and malaria programs. Among these, HIV/AIDS programs received the most funding, and tuberculosis the least [3]. Through 2012, the Global Fund determined funding eligibility based on country income, past and ongoing Global Fund grant performance, and, for upper-middle income countries, disease burden and development assistance from other sources [4]. 
The Global Fund actively supports program evaluations, although these have mostly focused on process measures rather than health outcomes [5, 6]. The Global Fund's annual Results Report calculate number of lives saved using models that rely on the efficacy of financed goods such as antiretroviral therapy (ART) to translate service delivery outputs into mortality benefits [7]. However, this approach does not account for differences between theoretical efficacy and real-world effectiveness, or for mortality changes that are unrelated to the Global Fund's support [8].

We provide a quantitative assessment of the relationship between Global Fund disbursements and subsequent changes in key health outcomes: all-cause adult mortality, all-cause under-five mortality, and malaria-specific under-five mortality. Quantifying the mortality changes related to Global Fund support is important for several areas of global health policy. First, understanding and optimizing the Global Fund's health outcomes has direct implications for the health of millions: the opportunity cost of ineffectiveness is high. Second, estimating the Global Fund's effectiveness makes an important contribution to the growing science of health aid effectiveness, and is an important input for measuring the value provided by the organization [9]. Third, additional data and analyses are needed to inform the broad policy questions over the extent to which health aid improves health outcomes. Finally, the Global Fund regularly implements changes to its resource allocation decisions to maximize impact, and understanding the Global Fund's overall relationship with mortality patterns, especially child mortality, where the Global Fund's impact is less certain, could provide important information for future strategic planning [10-12].

\section{Methods}

Approach

Our overall approach examines the relationship between Global Fund disbursement and longitudinal mortality trends among all countries ever eligible to receive Global Fund grants prior to and during the Global Fund's period of activity, from 1995 to 2010. The baseline period between 1995 and 2002 (prior to the Global Fund) allows us to analyze the role of pre-existing and baseline trends.

\section{Global fund support}

We analyzed data from all countries that ever received Global Fund disbursements, and countries that were eligible to apply for grants but did not receive any disbursements, between 2002 and 2010. Eligible non-recipients included several countries who had applied unsuccessfully, or whose eligibility had changed over time. In compiling support, we examined grant disbursements to individual countries as well as through multi-country grants. We allocated multi-country grants evenly among recipients $[8,13]$.
We operationalized Global Fund support (the principal exposure) as a continuous variable of Global Fund support per capita. Global Fund support was calculated as the total disbursements between 2002 and 2010, including multi-country grants. When examining all-cause adult and under-five mortality, we used Global Fund disbursements across all disease programs (HIV, TB, and malaria); however, we used only malaria grants when examining malaria-specific mortality. We denominated Global Fund disbursements by the population size as a measure of exposure because our intent was to look at the relationship of Global Fund disbursements with population-level changes in health outcomes. In addition, our assumptions about possible mechanisms of effectiveness flowed from disbursements to health through both treatment and prevention efforts, thereby rendering the entire population as potential beneficiaries.

To allow for the time elapsed from donor disbursements, in-country recipient expenditures on disease control programs, improved delivery of health services to the intended population, and mortality effects, our models lagged the earliest possible effect between disbursements and mortality by one year; we also capped the duration through which mortality effects could be detected at three years after the earliest year of putative effect $[14,15]$. For example, our models measured any mortality effects related to disbursements in 2002 over the period between 2003 and 2005.

\section{Mortality outcomes}

We focused on three mortality indicators: all-cause adult mortality, all-cause under-five mortality, and malariaspecific under-five mortality [16-18]. We included malaria-specific under-five mortality because it is a key impact indicator for the Global Fund, the disbursements devoted to malaria have increased substantially during the study period, and malaria makes up a sizable proportion of all-cause under-five deaths in many of the countries that receive Global Fund malaria grants [8, 19]. We used annual country-level mortality estimates produced by the Institute for Health Metrics and Evaluation (IHME) [16-18, 20]. Adult mortality was measured as the probability that a 15 -years-old person would die by age 59 (45q15); under-five mortality as the probability of dying before age 5 per 1000 live births (5q0); and malariaspecific under-five mortality as the probability of death from malaria per 1000 child-years at risk. We logtransformed all mortality rates to reduce skewness and because it facilitates an intuitive interpretation of changes in mortality as percentages. IHME estimates were used because they represent the most complete source of longitudinal mortality data in all countries of interest. The information used by IHME to generate its mortality estimates varies by country, but it does not include 
Global Fund (or any health aid) information in generating its estimates.

\section{Covariates}

We chose and specified four time-varying covariates to examine and adjust for important potential confounders of the relationship between Global Fund disbursements and mortality changes. First, we explicitly considered the possibility that the Global Fund targeted countries with relatively more capable health systems, so that improving outcomes may appear to be related to Global Fund support whereas in reality they reflect these countries' stronger underlying health system. We adjusted for health workforce density according to the Global Health Workforce Statistics database, defined as the number of physicians and nurses per 100,000 population [21, 22]. This indicator is closely related to measures of health system performance such as vaccination coverage and possibly reflects the capacity of recipient countries to effectively implement public health programs. Missing country-year observations were replaced with countryspecific mean, and a log-transformed density was used in the final analysis. We checked the sensitivity of the findings to the missing data by repeating the main analyses after dropping all missing data. This analysis did not substantively change the findings, and is not shown.

We used two covariates to represent the role of social and economic development as correlates of mortality changes: real gross domestic product per capita (GDPpc) measured in constant 2005 international dollars, and the percentage of population living in urban areas from the World Development Indicators [23]. Finally, we included health spending per capita [24]. Health spending may itself drive mortality reductions, and in addition may influence funding preferences: the Global Fund views health funding from recipient public sources ("Domestic counterpart Funding") favorably, and health expenditures are an indicator of preferential Global Fund support [25]. In addition to the time-varying covariates, all analyses included country fixed-effects to control for time-invariant differences among countries, including fixed baseline or pre-existing differences. For example, if the Global Fund made early commitments based on recipients' baseline health system capacity in 2002, that time-invariant difference is controlled for with country fixed effects.

\section{Statistical approach and sensitivity analyses}

We used panel fixed effect regressions that examine withincountry changes in mortality in relation to timing and levels of Global Fund disbursements. In the primary analysis, disbursements per-capita were interacted with a time trend variable. The coefficient thus represents the magnitude of the change from pre-existing mortality trends with each increase of $\$ 1$ per capita in Global Fund disbursements. All models included country fixed effects and the time-varying covariates. In addition, the health workforce density covariate was included as an interaction with the main effect parameters to examine for effect modification due to the Global Fund's possible funding selection based on health system capacity. The primary regression models, then, can be represented as follows:

$$
\begin{aligned}
& \text { Mortality }_{i t}=\gamma_{i}+\beta_{1} \times \text { trend }_{t} \\
& +\beta_{2} \times \text { trend }_{t} \times \text { FundPerCap }_{i t} \\
& +\beta_{3} \times \text { trend }_{t} \times \text { FundPerCap }_{i t} \\
& \times \text { Health WorkforceDensity }_{i t}+Z_{i t} \boldsymbol{\alpha}+\boldsymbol{X}_{i t} \boldsymbol{\delta}+\varepsilon_{i t}
\end{aligned}
$$

Where Mortality $_{i t}$ is the log-transformed mortality rates for country $i$ in year $t$, trend $d_{t}$ is a time trend taking on the value $t$ in the $\mathrm{t}^{\text {th }}$ year, FundPerCap $i t$ are the per-capita disbursements from the Global Fund, $H W D_{i t}$ is the health workforce density, $X_{i t}$ is a vector of country-year covariates including real gross domestic product per capita, health expenditures per capita and the percentage of population living in the urban area., and $\gamma_{i}$ denotes the fixed effect coefficient of country i. The terms that explicitly relate to the mortality trend are shown in the equation; the variables that are not interacted with $\operatorname{trend}_{t}$ are consolidated into the matrix term $\boldsymbol{Z}_{i t} \boldsymbol{\alpha}$. Robust standard errors clustered by country were calculated in all analyses. Additional regression details are in Additional file 1: S1 (Statistical Models).

Several additional analyses supported the main findings. First, we repeated the primary models in two subanalyses: one in country subsets divided into tertiles by HIV prevalence around the start of the Global Fund, and a second restricted to the subset of sub-Saharan African countries (Additional file 1: S2), because of the Global Fund's heavy investments and the unique disease burden of HIV, tuberculosis, and malaria in this region. Second, we examined the possibility that concurrent funding from the US President's Emergency Plan for AIDS Relief (PEPFAR) confounded the observed Global Fund effects. A variable identifying PEPFAR support was introduced alone and in interaction with the Global Fund disbursement variables to test for effect modifications (Additional file 1: S3). Third, we explored additional models, including controlling for health aid disbursements from organizations other than the Global Fund, added unadjusted models without covariates that may be influenced by Global Fund support, trimmed the most uncertain estimates, replaced time trends with year fixed effects, and added countryspecific time trends (Additional file 1: S4). Fourth, we varied the lag length between disbursements and possible start of mortality effects -1 year in the default analysis - to 2-4 years (Additional file 1: S5). Fifth, in assessing malaria mortality, we denominated disbursements per person at risk of malaria in each country (Additional file 1: S6), as alternative 
to per capita in the default analysis. As a final test of uncertainty, we used the mortality bounds provided by IHME to sample from the distribution of plausible values and repeated the analyses 1000 times to generate a distribution of estimated coefficients (Additional file 1: S7).

All analyses used Stata 13.1 (Statacorp Inc). All data sources are indicated in the paper. In addition, the analytic code is provided along with the article as Supporting Information files. Additional file 2 Additional file 3 and Additional file 4.

\section{Ethics}

This analysis has been assessed as exempt from ethics review by Stanford's Human Subjects Research \& IRB Office.

\section{Results}

\section{Baseline and descriptive findings}

We analyzed data from all countries that were eligible for support from the Global Fund up to 2010 (Fig. 1). The average total disbursements per-capita between 2002 and 2010 for all study countries was \$1.08 (in constant 2005 US dollars); in a wide distribution ranging from $\$ 0.1$ per capita among the lowest tertile of recipients to $\$ 2.68$ among the highest tertile of recipients
(Table 1). The Global Fund's per-capita disbursements increased three-fold during the period from 2007 to 2010, compared with its first five years of operation, from \$0.57 to \$1.73 Malaria funding also showed high variability when measured in disbursements per capita. Of the 51 countries in the highest tertile of per capita malaria disbursements, 28 were in sub-Saharan Africa. In 2002, average all-cause mortality among children and adults were 3 -fold and 2-fold higher, respectively, in the highest compared with the lowest tertile countries.

\section{Global fund and all-cause adult mortality}

Higher Global Fund disbursements per capita were followed by greater declines in adult mortality. Figure 2a shows the temporal pattern of adult mortality by tertile of Global Fund support. The Figure suggests that, prior to the Global Fund, adult mortality was rising among the countries that ended up as the highest recipients, that this rise slowed just prior to start of Global Fund disbursements, and that it changed into a decline following the initiation of support. A similar pattern, though less dramatic, is seen among countries in the middle tertile: rising adult mortality rates followed by a reversal of mortality rates following start of Global Fund disbursements. In contrast, countries at the lowest tertile of support experienced

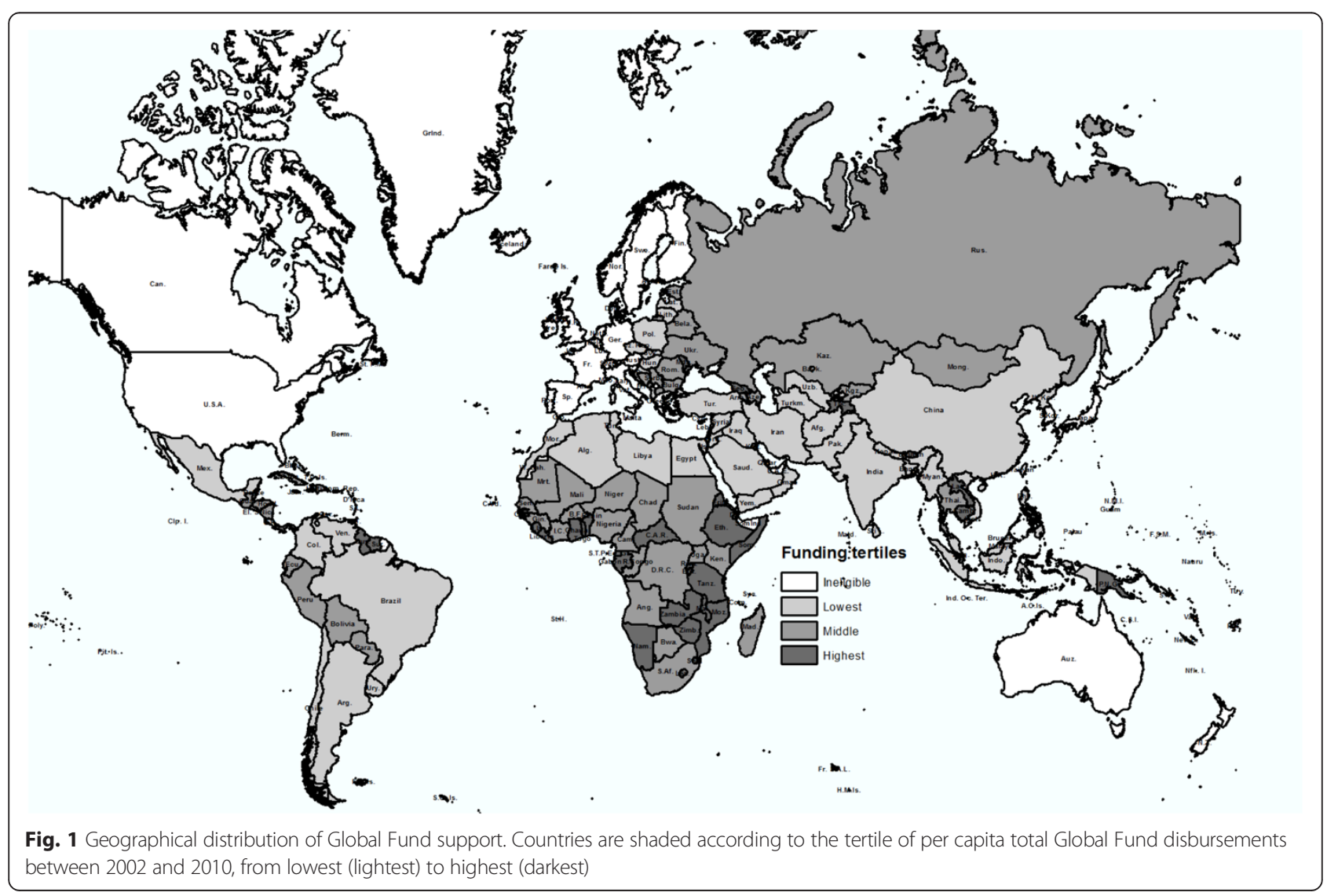


Table 1 Descriptive characteristics of countries, at different levels Global Fund per capita disbursements

\begin{tabular}{|c|c|c|c|c|c|}
\hline & All Eligible counties & Highest tertile & Middle tertile & Lowest tertile & $\%$ imputed data \\
\hline Number of countries & 152 & 51 & 51 & 50 & - \\
\hline $\begin{array}{l}\text { Average real GDP per capita in 2002-2010 } \\
\text { (in constant } 2005 \text { international dollar) }\end{array}$ & 6426 & 3720 & 5174 & 10,406 & $0 \%$ \\
\hline $\begin{array}{l}\text { Average public health expenditure per capita } \\
\text { (net of GF) in 2002-2010 (in constant } 2005 \text { US dollars) }\end{array}$ & 216 & 118 & 145 & 349 & $0.23 \%$ \\
\hline $\begin{array}{l}\text { Average percentage of population living in urban area } \\
\text { in 2002-2010 }\end{array}$ & 48 & 37 & 49 & 58 & $0 \%$ \\
\hline $\begin{array}{l}\text { Total Global Fund disbursements per capita } \\
\text { (in constant } 2005 \text { US dollars) }\end{array}$ & 1.08 & 2.68 & 0.71 & 0.10 & $0 \%$ \\
\hline $2002-2006$ & 0.57 & 1.40 & 0.38 & 0.05 & \\
\hline $2007-2010$ & 1.73 & 4.30 & 1.12 & 0.16 & \\
\hline \multicolumn{6}{|l|}{ All-cause adult mortality rate ${ }^{2}$} \\
\hline 1995 & 246 & 316 & 254 & 171 & $0 \%$ \\
\hline 2002 & 247 & 331 & 259 & 156 & $0 \%$ \\
\hline 2007 & 241 & 326 & 253 & 150 & $0 \%$ \\
\hline 2008 & 238 & 323 & 250 & 147 & $0 \%$ \\
\hline 2009 & 236 & 321 & 248 & 144 & $0 \%$ \\
\hline 2010 & 235 & 318 & 245 & 144 & $0 \%$ \\
\hline \multicolumn{6}{|l|}{ All-cause under-five mortality rate ${ }^{3}$} \\
\hline 1995 & 77 & 104 & 86 & 41 & $0 \%$ \\
\hline 2002 & 62 & 86 & 70 & 33 & $0 \%$ \\
\hline 2007 & 54 & 74 & 61 & 27 & $0 \%$ \\
\hline 2008 & 52 & 73 & 60 & 26 & $0 \%$ \\
\hline 2009 & 51 & 72 & 58 & 25 & $0 \%$ \\
\hline 2010 & 50 & 71 & 57 & 25 & $0 \%$ \\
\hline
\end{tabular}

Notes:

${ }^{1}$ Funding groupings used Global Fund disbursements for all sectors (HIV/AIDS, TB, malaria and Health Systems Strengthening)

${ }^{2}$ Adult mortality is expressed as the probability that a 15 -year-old person would die by age 59 per 1000 adults (45q15)

${ }^{3} \mathrm{Child}$ mortality is expressed as the number of deaths before age 5 per 1000 live births $(5 \mathrm{q} 0)$

declining mortality before Global Fund disbursements, and these declines continued along a similar trend after start of Global Fund support.

The regression results shown in Table 2 and Additional file 1: S2-S5 provide additional support for these relationships. We estimate that a $\$ 10$ increase in Global Fund disbursements per capita was followed by a $1.4 \%$ greater annual decline in all-cause adult mortality $(p=0.005)$. This effect was not significantly modified by an interaction with health workforce density, suggesting similar Global Fund effects on adult mortality irrespective of baseline or evolving national health system capacity. For example, in a country receiving Global Fund disbursements of \$10 per capita per year, and where all-cause adult mortality declined from 400 to 345 per 1000 adults over a 5-year period (a $3 \%$ annual decline), our analysis suggests that, absent the Global Fund, adult mortality would have dropped only from 400 to 369 per 1000 adults (a $1.6 \%$ annual decline). In a country like South Africa with approximately 28 million adults between 15 and 60 years old, these comparative mortality trends imply approximately 190,588 fewer adult deaths associated with 5 years of Global Fund support.

\section{All-cause under-five mortality}

Unlike for all-cause adult mortality, our analysis fails to indicate that any reductions in all-cause under-five mortality during the past decade could be attributed to Global Fund support. While the decline in under-five mortality was fastest in the countries receiving most assistance, there is no evidence of a subsequent acceleration in this trend after start of Global Fund disbursements (Fig. 2b). The regression analyses reflect these observations: changes in under-five mortality that may be attributable to the Global Fund are negligible and not statistically significant (Table 2). Similar to our findings with adult mortality, health workforce density did not significantly interact with the effect of Global Fund support. These findings make the possibility of spurious associations 


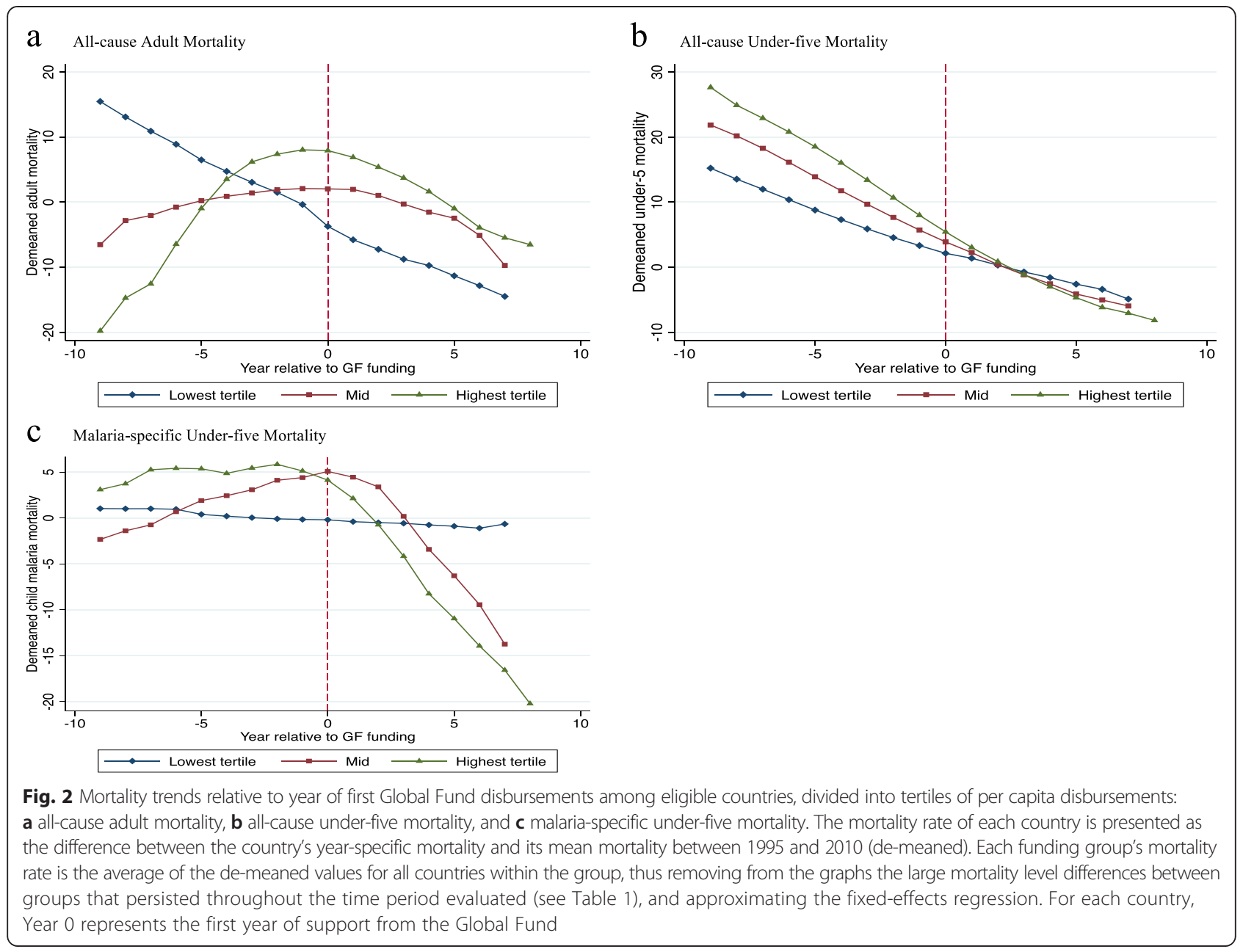

due to funding prioritization according to health system or program implementation capacity less likely.

\section{Malaria-specific under-five mortality}

We find evidence accelerating malaria-specific under-five mortality declines following Global Fund malaria disbursements. Figure $2 \mathrm{c}$ shows that a downward bend in malaria mortality trends among the top two tertiles of recipient countries started 1-2 years following initial Global Fund malaria disbursements. The regression analysis supports this impression: each $\$ 10$ increase in Global Fund disbursements per capita for malaria was associated with a $6.9 \%$ subsequent greater annual decline in malaria-specific under-five mortality. These findings were robust when Global Fund support was expressed per person living in areas at risk of malaria (Additional file 1: S5), instead of per capita of total national population in the default analysis. When restricting the analysis to sub-Saharan Africa, the magnitude of the malaria-specific mortality declines following Global Fund disbursements is lower (3.6 \%) and not statistically significant $(p=0.247)$.

\section{Sensitivity analyses}

The direction and size of observed associations were consistent across all-cause adult and all-cause child mortality specifications when repeating the analysis in the subset of Sub-Saharan countries only. When considering the findings in relation to countries' relative HIV burden, the declines in adult mortality were greatest in those countries with the highest baseline HIV prevalence, suggesting that reductions in HIV-related mortality have likely been instrumental in causing mortality declines (Additional file 1: S2).

We also examined the sensitivity of findings to possible synergy and/or confounding of Global Fund funding with PEPFAR funding, which clustered in an overlapping set of highest-recipient countries (Additional file 1: S3). We find that PEPFAR did not meaningfully modify the effect of the Global Fund for either adults or children. While past studies suggest that PEPFAR played a role in declining adult mortality, our findings suggest that this effect is independent from that of Global Fund support [26]. A final robustness check varied the lag duration between disbursement and start of possible mortality effects from 1 year (in 
Table 2 Relationship of Global Fund support to adult and under-five mortality changes

\begin{tabular}{llll}
\hline & $\begin{array}{l}\text { All-cause adult mortality } \\
(p \text {-value })^{5}\end{array}$ & $\begin{array}{l}\text { All-cause under-five mortality } \\
(p \text {-value })^{5}\end{array}$ & $\begin{array}{l}\text { Malaria-specific child mortality } \\
(p-v a l u e)^{5,6}\end{array}$ \\
\hline Global Fund \$ per capita & $-0.0014(0.005)$ & $-0.0005(0.33)$ & $-0.0069(0.033)$ \\
Global Fund \$ per capita X HWD ${ }^{2}$ & $0.0013(0.72)$ & $-0.0005(0.25)$ & $0.0016(0.40)$ \\
Health workforce density (HWD) ${ }^{2}$ & $-0.0021(0.090)$ & $-0.0022(0.11)$ & $-0.0094(0.15)$ \\
GDPpc (logged, in 2005 USD, PPP adjusted) ${ }^{3}$ & $-0.0587(0.16)$ & $-0.1484(0.067)$ & $-0.6625(0.032)$ \\
\% of urban population & $0.0010(0.77)$ & $-0.0050(0.23)$ & $0.0178(0.54)$ \\
Health expenditure per capita (logged, in 2005 USD) & $-0.0018(0.92)$ & $-0.0078(0.60)$ & $-0.0503(0.55)$ \\
Number of countries & 147 & 147 & 55 \\
Number of country-year observations & 2322 & 2322 & 856 \\
\hline
\end{tabular}

Notes:

${ }^{1}$ Global Fund disbursements per capita in constant 2005 USD. A significant negative coefficient indicates effectiveness of Global Fund in bending down the mortality trend. The coefficient indicates that the mortality rate declined by coefficient $\times 100$ percent faster per year for every $\$ 1$ increase in per capita disbursements

${ }^{2} \mathrm{HWD}$ is health workforce density, defined as the number of doctors and nurses per 100,000 population, an indicator of health system capacity. All HWD estimates were log-transformed. The interactions between HWD and the Global Fund variables indicate whether, at any level of Global Fund exposure, the observed outcomes changed based on HWD. The coefficient of the interactive term measures how the health workforce density in a country modifies the effectiveness of Global Fund in changing the mortality trend. There is no evidence that the effect of Global Fund on mortality was meaningfully different based on health system capacity as measured through HWD

${ }^{3}$ Gross domestic product per capita, log-transformed, in 2005 USD, adjusted for purchasing power parity

${ }^{4}$ Total health expenditures minus Global Fund disbursements from all sources per capita in 2005 USD

${ }^{5}$ Mortality rates are log-transformed, so that the coefficient values can be interpreted as the additional annual proportional change in mortality with each additional year of support from the Global Fund (see numerical examples in Results text)

${ }^{6}$ The malaria-specific models analyze countries with high, severe or extreme malaria burden. According to the Global Fund's eligibility criteria, these are the countries with burden defined as high, severe, or extreme; countries with low or moderate burden were excluded, resulting in the analysis of 55 countries.

Only malaria grants were used to examine malaria-specific mortality

the default analysis) up to 4 years (Additional file 1: S5). Extending the minimum lag between disbursements and mortality changes decreased the magnitude of the attributable reductions in malaria-specific under-five mortality.

\section{Discussion}

Our analysis on the relationship between grants from the Global Fund and mortality changes in recipient countries suggests that Global Fund disbursements were followed by accelerated reductions in all-cause adult mortality, and these mortality reductions increased with increasing Global Fund support. This relationship was most strongly observed in countries with a high HIV prevalence, consistent with the notion that large global health initiatives have played a role in the changing epidemiology of HIV-related and, thereby, allcause adult mortality. We also find a close relationship between malaria funding and accelerating declines in malaria-specific under-five mortality. However, we fail to find evidence that the Global Fund was associated with accelerated reductions in all-cause under-five mortality.

The lack of Global Fund effect on all-cause under-five mortality (despite large apparent effects on malaria-specific under-five mortality) requires further discussion. We observe an absence of change in child mortality trends following Global Fund grants. We speculate that Global Fund grants may have failed to contribute to accelerating child mortality declines because in many recipient countries the main causes of under-five mortality are diarrhea, pneumonia, and malnutrition (and not malaria, tuberculosis, or HIV), which Global Fund-supported disease programs do not target $[27,28]$. The absence of observed changes in allcause under- 5 mortality and declines in malaria-specific under-5 mortality may result from the use of different exposures as well as from the fact that malaria makes up a small portion of all-cause under-5 mortality in many countries. We also observe that the magnitude of the declines in malaria-specific under-5 mortality is smaller in sub-Saharan Africa compared with the overall sample (Additional file 1: S2). While we cannot explain this observation, we speculate that this could possibly be explained by the relatively high burden of falciparum malaria, relatively high transmission risk, unique vector control challenges, or less effective use of Global Fund resources in sub-Saharan Africa.

The lack of a relationship between disbursements and all-cause under-five mortality could inform ongoing Global Fund strategic decisions to expand its support beyond the three diseases, maximizing and leveraging synergies between supported disease control programs and neonatal, infant and child health strategies and systems more broadly [29]. These considerations are articulated in Global Fund documents, but under-five mortality reduction has not been a distinct strategic priority to date [12]. External Global Fund evaluations proposed approaches for exploiting synergies between malaria and integrated 
management of childhood illnesses as potential approaches to enhance the Global Fund's health impact, but such cross-program approaches have not been widely adopted to date. Our results furthermore suggest a role for measuring broad health indicators such as all-cause mortality to assess the contributions of large global health initiatives to population health.

We find a significant and robust effect on all-cause adult mortality, across all countries eligible for Global Fund support, within Sub-Saharan Africa as well as in the country subgroup with the highest HIV prevalence. In addition, we find that concurrent program funding from PEPFAR does not diminish the relationships between Global Fund support and all-cause adult mortality. Our analysis thus does not find support for a hypothesized antagonistic effect of large global health initiatives, such as those postulated to result from organizations that duplicate efforts while incurring administrative overheads without adding value [30].

\section{Limitations}

This analysis uses aggregated, smoothed mortality estimates that were generated using sophisticated demographic and epidemiological models [31]. While some studies question the data we use for all-cause under-five mortality and malaria mortality, especially among adults outside Africa, there is broader agreement on malariaspecific under-five mortality levels and trends, and the consensus around all-cause under-five mortality is growing for many countries (with the possible exception of some countries with high HIV burden) [32, 33]. In addition, the data sources underlying these mortality estimates (such as the Demographic and Health Surveys) are of high quality [16]. Our primary analyses use the point estimates generated by IHME, though the uncertainty from the underlying data-generating process may be substantial. We make an effort to address this uncertainty by trimming the least reliable observations, thereby emphasizing observations with less uncertainty (Additional file 1: S4). In addition, the data we use for adult mortality is arrived at using lagged, smoothed GDPpc estimates (among other predictor variables). The use of GDPpc as an input to our models leave open questions about our ability to adequately control for overall level of economic development. We considered other data sources for this analysis, including the United Nations Inter-agency Group for Child Mortality Estimation for under-5 mortality and the Demographic and Health Surveys (DHS). The DHS data is available for only approximately 90 countries, and less during the study period. We also preferred IHME data because it uses a consistent methodology and underlying data sources for estimating adult, child, and malariaspecific mortality, thus limiting the measurement challenges that might arise from using different estimation methods.

Our fixed effects approach relaxes some of the limitations to causal inferences from ecological associations, yet unmeasured drivers of mortality changes that may cluster with the Global Fund in time and in geographical distribution remain a concern. Notably, it is possible that receipt of Global Fund support may correlate with a country's intrinsic public health capacity [10]. Our inclusion of health system capacity measures (proxied by health workforce density), and their possible interaction with Global Fund funding, however, fail to support this concern. Another concern is that the observed declines in adult mortality may simply reflect the dynamic ebb of the HIV epidemic that would have occurred also without Global Fund funding. While this is not a hypothesis that our analysis can fully exclude, this is less likely to explain our findings given the Global Fund's large infusion of financial resources to ART programs, the high efficacy of ART in reducing mortality among HIV+ individuals, the dose-response relationship that we find, whereby greater Global Fund disbursements led to greater subsequent declines in mortality, and the dramatic reversal of adult mortality trends after the introduction of ART documented in other contexts [34, 35]. Strong causal inference is challenging in the absence of ex ante evaluation design or natural experiments, and our aim is to make a careful and measured attempt to estimate the Global Fund's impacts despite the challenging causal landscape.

While we accounted for possible interactions between the Global Fund and PEPFAR, as well as controlled for health aid besides the Global Fund, we did not assess interactions between Global Fund and other major multicountry donors such as the US President's Malaria Initiative [36]. Our study does not preclude additional important survival benefits from of concurrent economic development, health system improvement, and technological advancements; nevertheless, the multivariate panel regressions suggest that the Global Fund had an effect on accelerating adult mortality reductions. The observational approaches we used in this analysis demonstrate important associations of the Global Fund with mortality changes, but cannot prove a causal link. Rather, we show that the epidemiological evidence is consistent with three narratives: that the Global Fund played a role in the reduction of adult mortality, that it played a role in reducing malaria burden among children, and that it did not measurably contribute to all-cause mortality reductions among under- 5 children. We do not claim to prove these narratives, but rather raise the burden of proof for any claims to the contrary. The study provides a first-order estimate of the Global Fund's relationship with mortality changes, though the 
effects may be variable in smaller country subsets or individual countries.

\section{Conclusion}

Global Fund support was significantly associated with accelerated reductions in adult mortality and malariaspecific under-five mortality, across all recipient countries and within the subsample of Sub-Saharan countries, and independent from effects of PEPFAR's concurrent funding. However, we observe no significant association between Global Fund support and relative changes in all-cause under-five mortality. These findings are consistent with an important positive health impact achieved so far, as well as ongoing new opportunities for this global health initiative to further enhance its impact.

\section{Supplementary material}

Refer to Web version for supplementary material.

\section{Additional files}

Additional file 1: Appendix S1: Statistical Models; Appendix S2. Global Fund Effect in Country Subsets; Appendix S3. Global Fund Interactions with PEPFAR and Health Workforce; Appendix S4. Additional Specifications; Appendix S5. Analyses Using Different Lag Durations; Appendix S6. Malaria Funding Exposure per Person at Risk; Appendix S7. Sampling From Mortality Uncertainty Bounds. (DOCX 349 kb)

Additional file 2: Code for producing all-cause adult mortality findings. (DO $26 \mathrm{~kb}$ )

Additional file 3: Code for producing all-cause child mortality findings. (DO $26 \mathrm{~kb}$ )

Additional file 4: Code for producing under-five malaria mortality findings. (DO $21 \mathrm{~kb}$ )

\section{Competing interests}

All authors have completed the ICMJE uniform disclosure form at http://www.icmje.org/coi_disclosure.pdf.

We declare no financial or non-financial competing interests.

\section{Authors' contributions}

IY managed the research process, including model design, plot of figures, data management and analysis, interpretation of results, and co-wrote the first draft of the report. EK contributed to literature search, analysis design, plot of figures, data collection, analysis and interpretation, and the writing of the report. EB conceived the research idea, contributed to literature search, analysis design, data collection, analysis and interpretation, and co-wrote the first draft of the report. All authors read and approved the final manuscript.

\section{Authors' information}

Not applicable.

\section{Role of funding source}

EB is supported by the National Institutes of Allergy and Infectious Diseases and by the Doris Duke Charitable Foundation. The funding organizations had no role in the conception or execution of this analysis.

\section{Ethics committee approval}

Not applicable.

\section{Transparency Declaration}

I, the lead author (the manuscript's guarantor), affirm that the manuscript is an honest, accurate, and transparent account of the study being reported that no important aspects of the study have been omitted; and that any discrepancies from the study as planned (and, if relevant, registered) have been explained.

\section{Author details}

${ }^{1}$ Department of Economics and Finance, City University of Hong Kong, Tat Chee Avenue, Kowloon, Hong Kong. ${ }^{2}$ Department of Public Health, Erasmus MC, University Medical Center, Postbus 2040 3000CA, Rotterdam, The Netherlands. ${ }^{3}$ Avenir Health, Geneva, Switzerland. ${ }^{4}$ Division of General Medical Disciplines, Stanford University Stanford, Stanford, CA 94305, USA. ${ }^{5}$ Center for Health Policy and the Center for Primary Care and Outcomes Research, Stanford University, Stanford, CA 94305, USA.

Received: 20 March 2015 Accepted: 21 September 2015

Published online: 28 September 2015

\section{References}

1. Financing Global Health. Transition in an Age of Austerity. 2013. http://www.healthdata.org/policy-report/financing-global-health-2013-transitionage-austerity.

2. Cohen J. A hard look at global health measures. Science. 2014;345(6202):1260-5

3. The Global Fund. Disbursements in Detail [http://portfolio.theglobalfund.org/ en/Downloads/DisbursementsInDetail]. Accessed 24 September 2015.

4. The Global Fund to Fight AIDS, Tuberculosis, and Malaria. Eligibility, Counterpart Financing and Prioritization Information Note [http://www.theglobalfund.org/ en/fundingmodel/single/eligibility/. Accessed 24 September 2015.

5. Sherry J, Mookherji S, Ryan L. The Five-Year Evaluation of the Global Fund to Fight AIDS, Tuberculosis, and Malaria Synthesis of Study Areas 1, 2 and 3. Geneva: GFATM and Macro International; 2009

6. Global Fund Five Year Evaluation. Study Area 3. The Impact of Collective Efforts on the Reduction of the Disease Burden of AIDS, Tuberculosis, and Malaria. Calverton, MD: Macro International; 2009.

7. Strategic Investments for Impact. Global Fund Results Report 2012 [http://www.theglobalfund.org/en/publications/]. Accessed 24 September 2015.

8. McCoy D, Jensen N, Kranzer K, Ferrand RA, Korenromp EL. Methodological and policy limitations of quantifying the saving of lives: A case study of the global fund's approach. PLoS Med. 2013;10(10):e1001522.

9. Glassman A, Fan V, Over M, Silverman R, McQueston K, Duran D. More health for the money: A practical agenda for the Global Fund and its partners. A report of the Center for Global Development Working Group on Value for Money in Global Health. Consultation draft. 2013.

10. Policy On Eligibility Criteria, Counterpart Financing Requirements, And Prioritization Of Proposals For Funding From The Global Fund [http://www.theglobalfund.org/documents/board/23/ BM23_14PICPSCJEligibilityAttachment1_Policy_en/.]. Accessed 24 September 2015.

11. Modification of Grant Renewals and Transition to New Funding [http://www.theglobalfund.org/Knowledge/Decisions/GF/B25/DP16/]. Accessed 24 September 2015.

12. Strategy: The Global Fund Strategy 2012-2016: Investing for Impact [http://www.theglobalfund.org/documents/core/strategies/ Core_GlobalFund_Strategy_en/]. Accessed 24 September 2015.

13. Global Fund Grant Portfolio [http://portfolio.theglobalfund.org/en/Home/Index] Accessed 24 September 2015.

14. Korenromp EL, Hosseini M, Newman RD, Cibulskis RE. Progress towards malaria control targets in relation to national malaria programme funding. Malar J. 2013:12(1):18.

15. Akachi $Y$, Atun R. Effect of investment in malaria control on child mortality in sub-Saharan Africa in 2002-2008. PLoS One. 2011;6(6):e21309.

16. Rajaratnam JK, Marcus JR, Levin-Rector A, Chalupka AN, Wang H, Dwyer L, et al. Worldwide mortality in men and women aged 15-59 years from 1970 to 2010: a systematic analysis. Lancet. 2010;375(9727):1704-20.

17. Rajaratnam JK, Marcus JR, Flaxman AD, Wang H, Levin-Rector A, Dwyer $L$, et al. Neonatal, postneonatal, childhood, and under-5 mortality for 187 countries, 1970-2010: a systematic analysis of progress towards Millennium Development Goal 4. Lancet. 2010;375(9730):1988-2008.

18. Murray CJL, Rosenfeld LC, Lim SS, Andrews KG, Foreman KJ, Haring D, et al Global malaria mortality between 1980 and 2010: a systematic analysis. Lancet. 2012;379(9814):413-31. 
19. The Global Fund. Monitoring and Evaluation Toolkit [http://www.theglobalfund.org/documents/monitoring_evaluation/ ME_MonitoringEvaluation_Toolkit_en/]. Accessed 24 September 2015

20. Institute for Health Metrics and Evaluation. GHDx - Global Health Data Exchange [http://www.healthdata.org/about/ghdx]. Accessed 24 September 2015.

21. World Health Organization. Global Health Workforce Statistics [http://www.who.int/hrh/statistics/hwfstats/en/]. Accessed 24 September 2015.

22. Anand S, Bärnighausen T. Health workers and vaccination coverage in developing countries: an econometric analysis. Lancet. 2007;369(9569):1277-85.

23. World Development Indicators Online (WDI) [databank.worldbank.org/]. Accessed 24 September 2015

24. Dieleman JL, Graves CM, Hanlon M. The fungibility of health aid: reconsidering the reconsidered. J Dev Stud. 2013;12:1755-1762.

25. The Global Fund. Counterpart Financing [http://www.theglobalfund.org/en/ fundingmodel/counterpartfinancingwtp/]. Accessed 24 September 2015.

26. Bendavid E, Holmes C, Bhattacharya J, Miller G. HIV Development Assistance and Adult Mortality in Africa. JAMA. 2012;307(19):2060.

27. Black RE, Cousens S, Johnson HL, Lawn JE, Rudan I, Bassani DG, et al. Global, regional, and national causes of child mortality in 2008: a systematic analysis. Lancet. 2010;375(9730):1969-87.

28. Black RE, Victora CG, Walker SP, Bhutta ZA, Christian P, de Onis M, et al. Maternal and child undernutrition and overweight in low-income and middle-income countries. Lancet. 2013;382:427-51

29. Cometto G, Ooms G, Starrs A, Zeitz P. A global fund for the health MDGs? Lancet. 2009;373(9674):1500-2.

30. Garrett L. Challenge of Global Health. Foreign Aff. 2007:86:14.

31. Murray CJL, Vos T, Lozano R, Naghavi M, Flaxman AD, Michaud C, et al. Disability-adjusted life years (DALYs) for 291 diseases and injuries in 21 regions, 1990-2010: a systematic analysis for the Global Burden of Disease Study 2010. Lancet. 2013;380(9859):2197-223.

32. Alkema L, You D. Child Mortality Estimation: A Comparison of UN IGME and IHME Estimates of Levels and Trends in Under-Five Mortality Rates and Deaths. PLoS Med. 2012;9(8):e1001288.

33. Global Burden of Disease Estimates. Secret Recipes or Spoiled Ingredients? [http://www.cgdev.org/blog/global-burden-disease-estimates-secret-recipesor-spoiled-ingredients]. Accessed 24 September 2015.

34. Palella Jr FJ, Delaney KM, Moorman AC, Loveless MO, Fuhrer J, Satten GA, et al. Declining morbidity and mortality among patients with advanced human immunodeficiency virus infection. N Engl J Med. 1998;338(13):853-60.

35. US Centers for Disease Control and Prevention. HIV Surveillance Reports [http://www.cdc.gov/hiv/library/reports/surveillance/]. Accessed 24 September 2015.

36. PMI President's Malaria Initiative. Saving Lives in Africa [http://www.pmi.gov/]. Accessed 24 September 2015

\section{Submit your next manuscript to BioMed Central and take full advantage of:}

- Convenient online submission

- Thorough peer review

- No space constraints or color figure charges

- Immediate publication on acceptance

- Inclusion in PubMed, CAS, Scopus and Google Scholar

- Research which is freely available for redistribution 